\title{
STABILIZATION OF CLAY SOILS USING FLY ASH
}

\author{
Mamadou Lamine DIALLO ${ }^{1}$, Yesim Sema UNSEVER ${ }^{1 *}$ \\ ${ }^{1}$ Civil Engineering Department, Natural and Applied Science Institute, Bursa Uludağ University, Bursa, 16059, \\ Turkey
}

Received: May 13, 2019; Accepted: June 17, 2019; Published: July 01, 2019

\begin{abstract}
Nowadays, environmental pollution is a serious problem in the world. Thermal power plants are used in many countries to meet the energy needs of growing cities. A lot of quantity of Fly Ash is produced while this energy is generated. Using such waste materials in construction offers significant advantages over current admixtures because they are typically less costly and provides environmental protection. Therefore, in recent years, researchers have been exploring new solutions for the use of such waste materials. In this study, the effect of $2 \%$ lime and different percentages of Orhaneli fly ash added to a clay soil taken from Bursa Uludağ University campus has been investigated. By using the sieve and hydrometer analysis and Atterberg Limit tests, the soil classification has been made. The optimum water content and maximum dry density of the mixtures were determined by the normal compaction test. In order to assess the strength of the mixtures, unconfined compression tests were carried out after various curing times ( 3 days, 7 days and 28 days). As a result of the experiments, it was found that adding lime and fly ash into the clay soil by different percentages increases the strength of the high plasticity clay in varying ratios.
\end{abstract}

Keywords: Fly ash, Clay, Unconfined compression test, Curing time, Soil stabilization

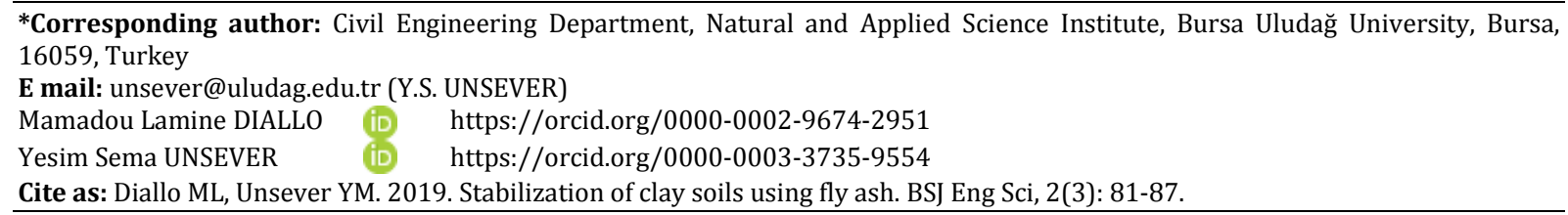

\section{Introduction}

Soft clay is found generally in a lot of regions around the world. These type clay soils are generally characterized by poor bearing capacity and swelling due to the change in the moisture content and high compressibility. In contact with water, high volume change potentials of these soils cause serious damages to constructions which are founded on them. For example, in the United States of America, the cost of damages caused by expansive soils behaviour is estimated at around $\$ 9$ billion every year (Estabragh et al., 2013). The most common and economical method for the stabilization of such soils is using admixtures that modify their mechanical properties and prevent volume changes.

There are varieties of methods for soil improvement. The choice of a particular soil stabilizer depends on many factors. Among these factors, the most important ones are the nature and the type of the soil, the type and importance of the project, the purpose of the stabilization, the desired engineering properties, the environmental conditions, the availability of the stabilizer and the economy of the project (Dallas and Nair, 2009).

Soil stabilization is a technique that aims to improve the soil strength and increase its resistance to softening by water and make it suitable for specific engineering 
projects (Sherwood, 1993). The usual admixtures in soil stabilization are lime, cement, fly ash etc. (Hayashi, 1999). Lime is mostly used in the stabilization of expansive soil for controlling swell and shrinkage behaviour. The $\mathrm{CaCl}_{2}$ and the $\mathrm{NaOH}$ contained in lime in different percentage develop strong lime alteration and generate soil lime pozzolanic reactions. The soil volume change potential is controlled by the lime modification reaction, which produces cementitious products. When an expansive soil is stabilized by lime, there are a diminution of the plasticity index and an enhancement of the unconfined compression strength (Thygaraj et al., 2012). Lime is one of the most effective additives as a stabilizer of finegrained soils. It highly reduces the plasticity of the soil and increases its workability. The treated soils engineering characteristics improvement vary depending on its type, the type of lime used, the percentage of lime and the curing time (Tosun et al., 2000).

The using of admixtures like cement and lime adds additional cost in the construction. In the last years, the employment of waste materials in the stabilization of problematic soils is highly encouraged as it promotes more sustainable construction, provides nature protection and decreases the cost of the project (Hasan et al., 2016; Puppala et al., 2016; Zhang et al., 2017). When a clay soil is stabilised by limestone dust, its strength properties and the plastic limit increase while the liquid limit and the plasticity index decrease (Sabat et al., 2015). The huge quantity of fly ash produce in the thermal power plants creates many unwanted environmental and economic problems. Some of these negative effects can be avoided by increasing the utilisation of fly ash in soil stabilisation (Hausmann et al., 1990). During the last decades, a lot of studies on the utilisation of fly ash in soils stabilisation have been conducted and the results showed that it can effectively improves the engineering properties of weak soils, especially its strength (Kolias et al., 2005; Prabakar et al., 2004; Wasemiller et al., 1997).

Fly ash is a waste product obtained during the combustion of pulverized coal in electric power station. According to its chemical composition, it is divided into 2 main classes: class $\mathrm{C}$ and $\mathrm{F}$. Class $\mathrm{C}$ fly ashes are produced from burning sub-bituminous coal and because of the high content of $\mathrm{CaO}$ (15\% to $35 \%$ ), it has high cementing properties. Thus, it can be used effectively as a binder material without an activator in soil stabilisation. Class $\mathrm{F}$ fly ashes contain low quantity of $\mathrm{CaO}$. That is why, it has not cementing properties. However, when it reacts with lime, cementing occurs and can be used in soil stabilization (Tumluer, 2006).

Saeid et al. (2012) stated that the combination of lime and fly ash would be more effective than the use of only lime or fly ash in soil stabilisation.

Ünver (2015) is investigated experimentally the usability of Soma and Çatalağzı Fly Ash in the stabilisation of low plasticity clay soil. For this, $5 ; 10 ; 15 ; 20 ; 25$ and $30 \%$ Fly Ashes were added to the clay and Unconfined
Compression Test (UCT), swelling and dispersibility tests have been performed on the prepared samples. According to the obtained results from the experiments, the strength, the swelling and the dispersibility of the clay soil were improved. Soma Fly Ash has been found to be more effective in improving the engineering properties of clay soil than Çatalağzı Fly Ash.

Ferguson (1993) is investigated the effect of fly ash on six different soils and concludes that there is an important diminution of the potential of soil swelling. The study shows that the swelling potential decreased to $0.8 \%$ with the addition of $16 \%$ fly ash to a clay soil with a swelling potential of $14 \%$.

In this study, the effect of $2 \%$ lime and different percentages of Orhaneli fly ash added to a clay soil, taken from Bursa Uludag University campus was investigated by using Atterberg limits tests, normal compaction tests and unconfined compression tests. As a result of the experiments, it is observed that the utilisation of lime and Orhaneli Fly Ash in the stabilisation of clay soils achieves a significant improvement on its geotechnical properties which was also suggested at previous studies (Hausmann et al., 1990; Kolias et al., 2005; Prabakar et al., 2004; Wasemiller et al., 1997).

\section{Material and Method}

In this study, $2 \%$ lime and 5\%, 10\%, 15\%, 20\%, 25\%, $30 \%$ of Orhaneli Fly Ash were mixed with the natural soil sample in order to investigate whether or not the utilisation of the material improved the engineering properties of the clay soil itself. The maximum dry density (MDD) values and the optimum moisture content (OMC) of the samples were obtained by using the normal compaction test. To determine the strength of the mixtures, cylinders of $38 \mathrm{~mm}$ diameter and $76 \mathrm{~mm}$ length were prepared with the optimum water content for each sample. The samples were kept in the desiccator during the curing time. After 3 days, 7 days and 28 days curing time, Unconfined Compression Test (UCT) has been conducted. Finally, for each sample, Atterberg Limits has been determined.

\subsection{Materials}

Three materials have been used in this study: clay, lime and Orhaneli fly ash (OFA). First, their geotechnical properties were determined by performing different laboratory tests. After that, the mentioned mixtures were prepared and subjected to proctor compaction, Atterberg limits and unconfined compressive tests. Finally their potential use in soil stabilisation was evaluated.

\subsubsection{Clay soil}

The soil used in the research has been taken from a construction site in Bursa town inside the Bursa Uludag University campus. By carrying out the necessary laboratory tests, basic properties of the clay have been 
determined. The obtained laboratory test results can be seen in Table 1.

Table 1. Basic properties of the clay

\begin{tabular}{ccccccc}
\hline $\begin{array}{c}200 \# \\
(\%)\end{array}$ & LL & PL & PI & $\begin{array}{r}\text { W } \\
(\%)\end{array}$ & Gs & Class \\
\hline 77.49 & 51.80 & 29.10 & 22.70 & 18.30 & 2.67 & $\mathrm{CH}$ \\
\hline
\end{tabular}

Grain size distribution was determined by sieve analysis and hydrometer test according to ASTM D2487 - 18 (ASTM D-2487-98, 1998). The grain size distribution result is shown in Figure 1. From the test, it is observed that $77.49 \%$ of the clay passes over the No\#200 sieve. From Figure 1 and Table 1 the soil is classified as High Plasticity Clay $(\mathrm{CH})$ according to USCS.

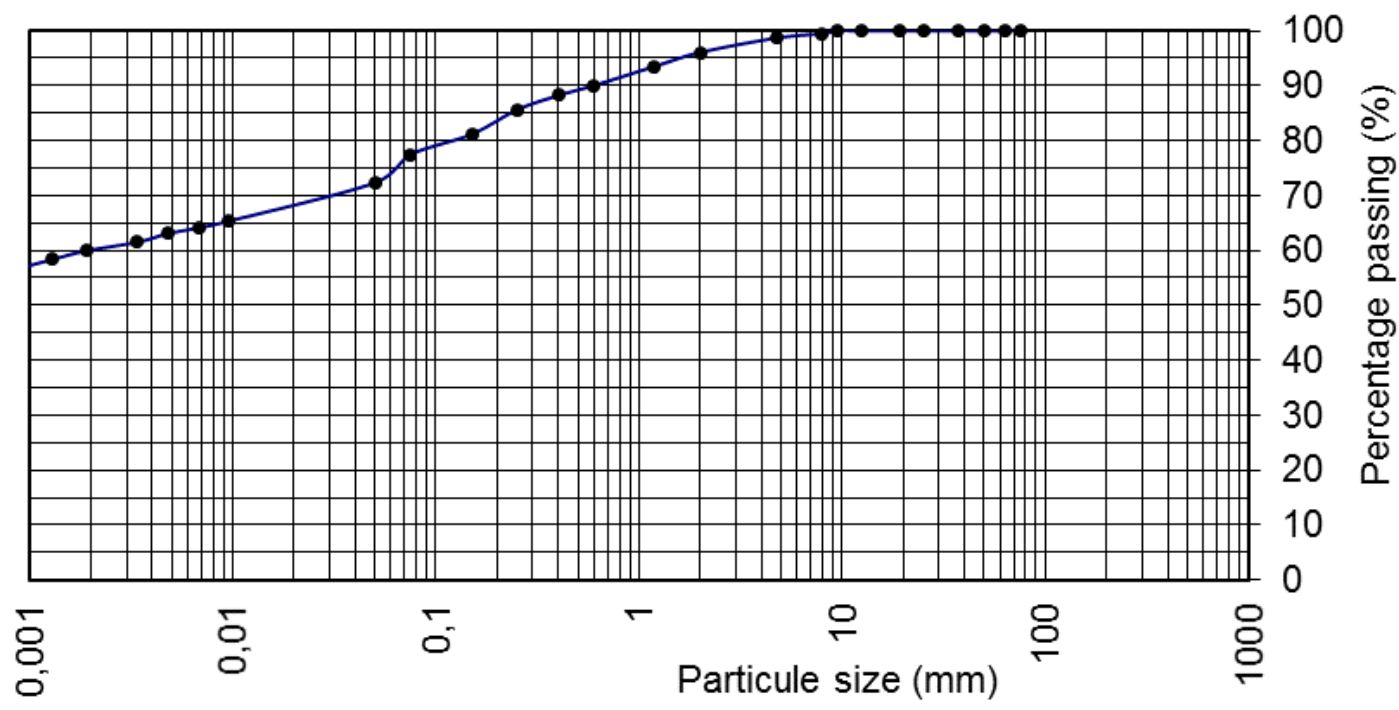

Figure 1. Grain size distribution of the clay

\subsubsection{Orhaneli fly ash (OFA)}

The Fly Ash (FA) used in this study is from ORHANELI electric power plant in BURSA, the location of the power plant is given in Figure 2.

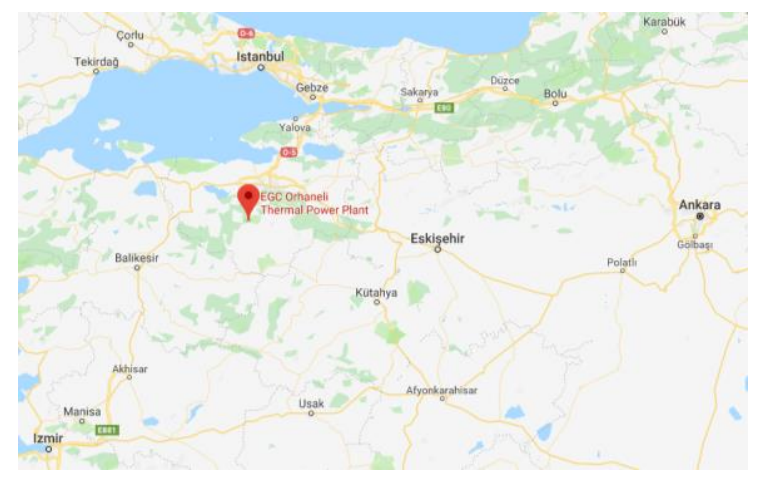

Figure 2. The location of the Orhaneli Electric Power Plant

The fly ash is grey-coloured; having specific gravity of 2.41 and according to the USCS it is a non-plastic (NP) material. In order to determine the chemical composition of the OFA and the other materials used in the study, XRF technique was carried out. According to the obtained results, the fly ash is mainly constituted by $32.62 \%$ of silica $\left(\mathrm{SiO}_{2}\right), 17.36 \%$ of alumina $\left(\mathrm{Al}_{2} \mathrm{O}_{3}\right), 6.97 \%$ of iron oxide $\left(\mathrm{Fe}_{2} \mathrm{O}_{3}\right)$ and $25.23 \%$ of calcium oxide ( $\left.\mathrm{CaO}\right)$. The amount of $\mathrm{SiO}_{2}+\mathrm{Al}_{2} \mathrm{O}_{3}+\mathrm{Fe}_{2} \mathrm{O}_{3}$ is more than $50 \%$. Thus according to the ASTM, the OFA belongs to the class C. Also, it contain a great amount of calcium oxide contained $25.23 \%$ which enhance its binding characteristic.

\subsubsection{Lime}

Hydrated lime, commercially available in Bursa, was used in the study. The specific gravity of the lime is 2.61 . The chemical analysis result shows that, it is essentially constituted by calcium oxide $(71.23 \%)$. Therefore it can improve the soil particle by bonding them together and restrain its swelling and shrinkage potential.

The chemical composition of the all materials used in the experiments and the percentage of each of them were determined by the XRF test and presented in Table 2 .

\subsection{Sample Preparation and Testing Method}

According to ASTM D 2216 (ASTM-D 2216 - 98, 1998), the soil was sieved over a \#40 sieve to eliminate the bigger particles, and samples were prepared. The clay soil was mixed with $2 \%$ of lime and OFA in different ratio in order to investigate its effect on engineering properties of the clay soil (Table 3). 
Table 2. Chemical composition of the materials used in the experiments

\begin{tabular}{lccc}
\hline Component & Clay (\%) & Lime (\%) & FA (\%) \\
\hline $\mathrm{SiO}_{2}$ & 61.21 & 0.79 & 38.62 \\
$\mathrm{Al}_{2} \mathrm{O}_{3}$ & 11.47 & 0.29 & 17.36 \\
$\mathrm{Fe}_{2} \mathrm{O}_{3}$ & 5.13 & 0.11 & 6.97 \\
$\mathrm{CaO}$ & 6.27 & 71.23 & 25.23 \\
$\mathrm{MgO}$ & 1.65 & 0.55 & 2.38 \\
$\mathrm{SO}_{3}$ & 0.12 & 1.79 & 5.38 \\
$\mathrm{Na}_{2} \mathrm{O}$ & 0.49 & 0.01 & 0.24 \\
$\mathrm{~K}_{2} \mathrm{O}$ & 1.20 & 0.05 & 1.87 \\
$\mathrm{KK}$ & 10.86 & 25.52 & 0.47 \\
\hline
\end{tabular}

Table 3. Clay, lime and flay ash mixture samples

\begin{tabular}{ccccc}
\hline & $\begin{array}{c}\text { Clay } \\
(\%)\end{array}$ & $\begin{array}{c}\text { Lime } \\
(\%)\end{array}$ & FA (\%) & Code \\
\hline 1 & 100 & 2 & 0 & $\mathrm{C}$ \\
2 & 98 & 2 & 0 & 2L \\
3 & 93 & 2 & 5 & 2L5FA \\
4 & 88 & 2 & 10 & 2L10FA \\
5 & 83 & 2 & 15 & 2L15FA \\
6 & 78 & 2 & 20 & 2L20FA \\
7 & 73 & 2 & 25 & 2L25FA \\
8 & 68 & 2 & 30 & 2L30FA \\
\hline
\end{tabular}

\section{Results and Discussion}

The effect of the addition of $2 \%$ limes with $5 \%, 10 \%$, $15 \%, 20 \%, 25 \%$ and $30 \%$ of Orhaneli Fly Ash to a high plastic clay soil on Atterberg limits, Compaction characteristics and Unconfined Compression Strength (UCS) have been investigated. In the experimental results, it can be seen that there is a good effect on the geotechnical properties of the clay when $2 \%$ lime and Orhaneli Fly Ash are added. They are summarized as follows:

\subsection{Atterberg Limits Test}

To investigate the plasticity change of the soil, lime and fly ash mixtures, Atterberg Limit tests were performed on those mixtures after 28 days curing time according to ASTM D 4318-2009 (ASTM D 4318-2009). The obtained results are shown in Table 4.
Table 4. Atterberg limits of the soil mixtures after 28 days curing

\begin{tabular}{ccccc}
\hline & LL (\%) & PL (\%) & PI (\%) & CLASS \\
\hline C & 51.80 & 29.10 & 22.70 & CH \\
2L & 49.60 & 35.92 & 13.68 & ML \\
2L5FA & 49.22 & 39.20 & 10.02 & ML \\
2L10FA & 48.96 & 41.32 & 7.64 & ML \\
2L15FA & 48.32 & 44.50 & 3.82 & ML \\
2L20FA & - & - & - & NP \\
2L25FA & - & - & - & NP \\
2L30FA & - & - & - & NP \\
\hline
\end{tabular}

By adding 2\% lime and Fly Ash to the clay, the LL and the PI of the clay decrease while the plastic limit increases. As it can be seen in Table 4, a slight decrease in LL and a clear decrease in PI were observed when the lime and the OFA were added to the soil. The PI values decreased from 22.7 to 3.83 by adding $2 \%$ lime and $15 \%$ OFA, after adding $2 \%$ lime and more than $15 \%$ OFA the soil lost completely its plasticity.

\subsection{Proctor Compaction Test}

Compaction characteristics of Clay-lime-OFA mixtures were studied by using the Standard Proctor test. Standard compaction test uses a mould of volume 948 $\mathrm{cm}^{3}$, and the wet soil is compacted in 3 equal layers and each layer receiving from a $2.5 \mathrm{~kg}$ hammer with a free fall of $30.5 \mathrm{~cm}$ of 25 blows. The experiment is repeated on five or more samples and the compaction curve is plotted with the obtained results. The MDD and the OMC can be easily determined with the plotted curve (ASTM D-698- 07, 2007).

In compaction tests, dry densities increase to the point of MDD by increasing the moisture content of the mixtures. After that, further augmentation in moisture content results to a diminution of the dry density. The OMC $\left(W_{\text {opt }}\right)$ is the water content corresponding to the maximum dry density. In order to obtain the compaction curves, dry densities of the samples with the corresponding moisture contents were plotted. The relation of the MDD and the OMC of the soil sample mixtures is shown in Figure 3.

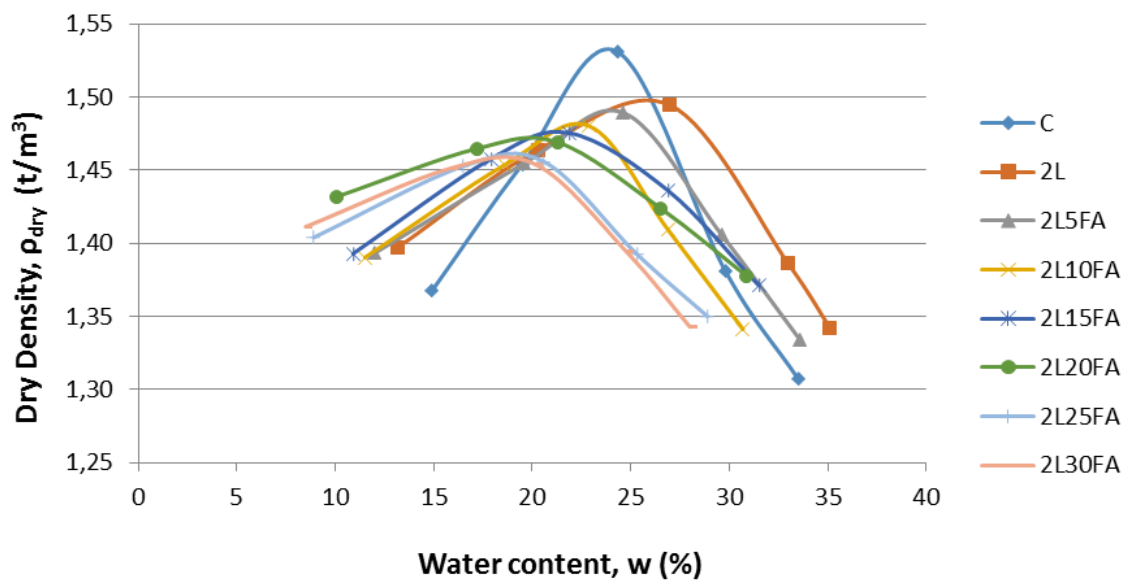

Figure 3. Compaction test result 
It is observed that by adding $2 \%$ of lime to the clay, the maximum dry density of the mixture decreases while the optimum water content increases from $23.6 \%$ to $26 \%$. By adding OFA, both of the maximum dry density and the optimum water content decrease. With $2 \%$ Lime, when the OFA content increase from 0 to $30 \%$, maximum dry density decreases from $1.53 \mathrm{t} / \mathrm{m}^{3}$ to $1.42 \mathrm{t} / \mathrm{m}^{3}$ and the OMC of the soil decreases from $23.9 \%$ to $18.1 \%$, which are summarized in Table 5.

Table 5. Summary of compaction test result

\begin{tabular}{ccc}
\hline & $\rho_{\text {dry,max }}\left(\mathrm{t} / \mathrm{m}^{3}\right)$ & $\mathrm{W}_{\text {opt }}(\%)$ \\
\hline $\mathrm{C}$ & 1.53 & 23.9 \\
2L & 1.49 & 26.0 \\
2L5FA & 1.49 & 24.8 \\
2L10FA & 1.46 & 22.5 \\
2L15FA & 1.45 & 21.0 \\
2L20FA & 1.44 & 19.9 \\
2L25FA & 1.43 & 19.0 \\
2L30FA & 1.42 & 18.1 \\
\hline
\end{tabular}

\subsection{Unconfined Compression Test (UCT)}

UCT is used to determine the unconfined compressive strength of the soil, quickly. For the test, the samples of $76 \mathrm{~mm}$ height and $38 \mathrm{~mm}$ diameter were prepared by compacting the mixtures to their MDD and to their corresponding OMC. To prevent moisture loss, the samples stay in desiccators during the curing period (ASTM D-2166 - 06, 2006). A total of 72 samples have been prepared. The reported UCS is the average of 3 cylindrical samples of each mixture at a specific curing time. Figure 4 shows the UCT test setup and tested soil samples.

The effect of lime and different percentage of Orhaneli Fly Ash on UCS of clay soil after 3 days, 7 days and 28 days curing time is presented in Figure 5 . From the results it can be seen that a good improvement of the UCS of the soil is obtained by adding the OFA up to $25 \%$. The curing time is one of the principal factors affecting the strength of lime and OFA stabilized clay soil as shown in Figure 4. As an example, the $\mathrm{q}_{\mathrm{u}}$ of the 2L25FA mixture after 3 days curing time is $16.17 \mathrm{~kg} / \mathrm{cm}^{2}$ while it is 38.99 $\mathrm{kg} / \mathrm{cm}^{2}$ after 28 days (Table 6).

Table 6. Unconfined compression test results

\begin{tabular}{crrr}
\hline Samples & \multicolumn{3}{c}{$\left.\mathrm{qu}_{\mathrm{u}} \mathrm{kg} / \mathrm{cm}^{2}\right)$} \\
\cline { 2 - 4 } & 3 Days & 7 Days & 28 Days \\
\hline $\mathrm{C}$ & 1.14 & 1.16 & 1.16 \\
2L & 3.87 & 4.83 & 5.10 \\
2L5FA & 6.65 & 11.11 & 12.87 \\
2L10FA & 9.56 & 13.94 & 20.80 \\
2L15FA & 11.68 & 16.59 & 29.40 \\
2L20FA & 14.56 & 20.67 & 34.21 \\
2L25FA & 16.17 & 23.11 & 38.99 \\
2L30FA & 15.53 & 21.37 & 36.27 \\
\hline
\end{tabular}

The plotted curves indicate that the maximum value of $\mathrm{q}_{\mathrm{u}}$ was reached after 28 curing days when the Fly Ash amount was $25 \%$. The results from the test showed that lime and Fly Ash stabilization is an effective treatment to the soil in order to improve its strength. The stabilizers effect on the strength of the clay soil is summarized as follow;

-It is observed that by adding $2 \%$ lime and Fly Ash to the clay soil, there is a good increase in the strength of the soil,

-The maximum UCS is obtained, when $73 \%$ of soil blends with $2 \%$ of lime and $25 \%$ of Fly ash,

-There is a great increase of the UCS with the curing time, -The best Soil-Fly Ash-Lime ratio for strengthening the weak clay soil is $73 \%-25 \%-2 \%$, respectively.

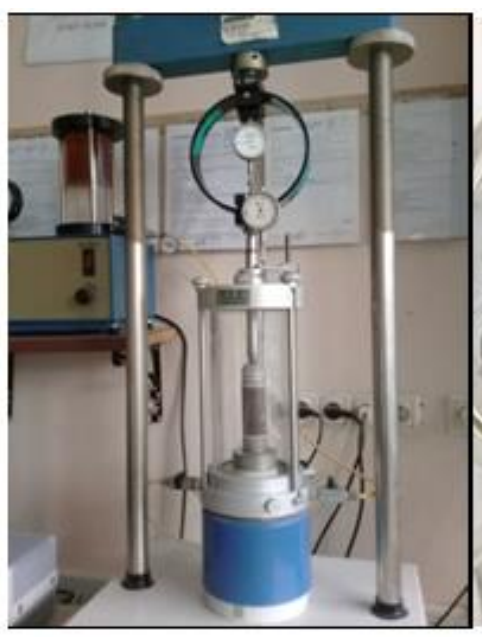

a) UCT machine

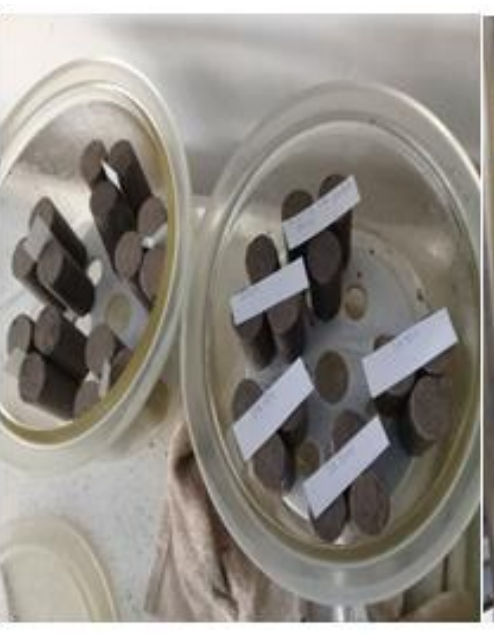

b) The prepared cylindrical samples

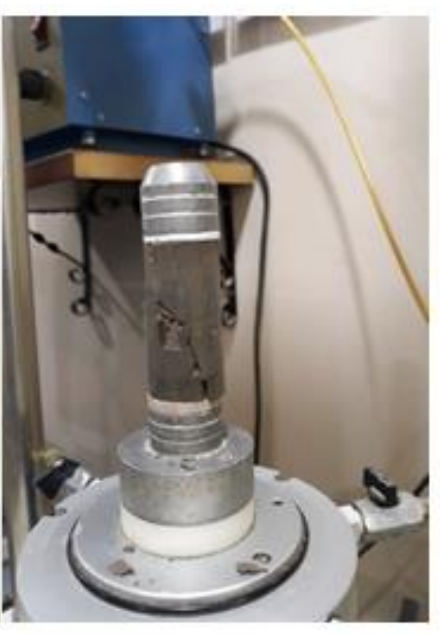

c) Soil sample after the test

Figure 4. Unconfined compression test 


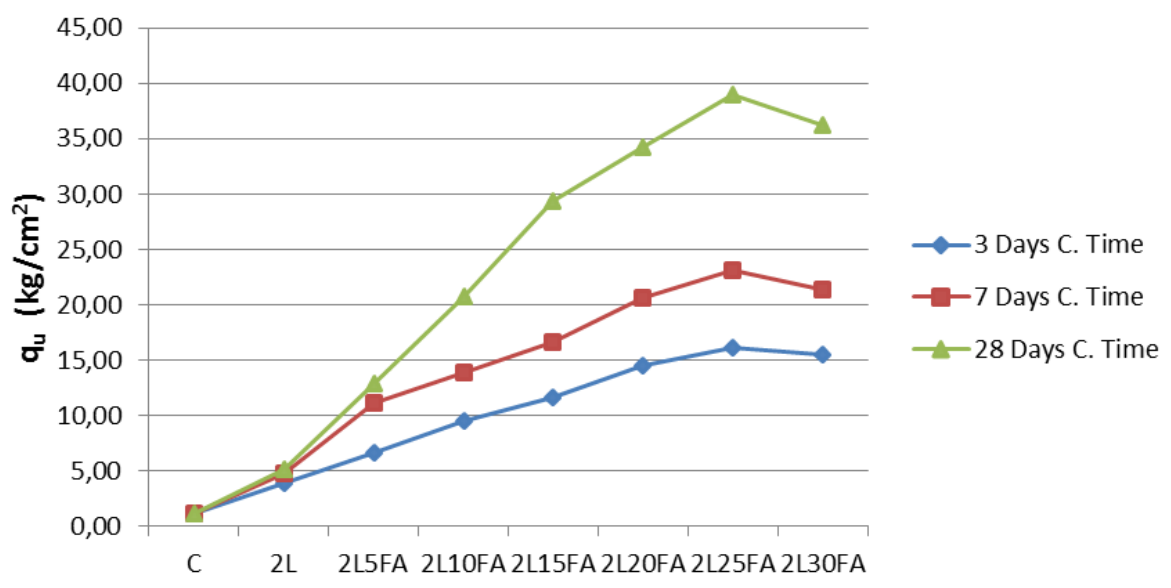

Figure 5. The effect of the used materials on UCS of clay

\section{Conclusions}

In this study, the effect of $2 \%$ lime and different percentage of Orhaneli Fly Ash on a high plasticity clay soil has been investigated. After adding $2 \%$ of lime and $15 \%$ of fly ash, the soil lost its plasticity and became non plastic soil. As a result of the experiments, it was found that the different ratios of mixtures increased the strength of the high plasticity clay in different percentages. Curing time also affected the strength of the samples in positive way.

The usage of waste material like fly ash in soil stabilisation has a very good environmental effect by avoiding the use of current admixtures like cement and by keeping them out of landfills. Thus, there are economic and environmental benefits of the use of Orhaneli Fly Ash in the stabilisation of clay soils.

As a further study, the effect of fly ash on swelling and shrinkage behaviour of high plastic clay will be investigated.

\section{Conflict of interest}

The authors declare that there is no conflict of interest.

\section{Acknowledgements}

The authors appreciated the support of Bursa Test for the experiments of this research.

\section{References}

Anonymous. 1998. ASTM D-2487-98 Standard practice for classification of soils for engineering purposes. American Society for Testing and Materials, USA.

Anonymous. 1998. ASTM-D 2216 - 98, Standard test method for laboratory determination of water (Moisture) content of soil and rock by mass. American Society for Testing and Materials, USA.

Anonymous. 2005. ASTM D-4318 - 05, Standard test methods for liquid limit, plastic limit, and plasticity index of soils. American Society for Testing and Materials.

Anonymous. 2005. ASTM D-698, Standard test methods for laboratory compaction characteristics of soil using standard effort. American Society for Testing and Materials, USA.

Anonymous. 2016. ASTM D-2166 - 06, Standard test method for unconfined compressive strength of cohesive soil. American Society for Testing and Materials.

Armin R, Behzad K. 2013. Stabilization of clayey soil with lime and waste stone powder. Inter J Sci Res Know, 1(12): 547556, 2013.

Dallas NL, Nair S. 2009. (NCHRP), Recommended practice for stabilization of subgrade soils and base materials. Web-Only Document 144, Project 20-07, August 2009.

Du Y, Li S, Hayashi S. 1999. Swelling-shrinkage properties and soil improvement of compacted expansive soil, Ning-Liang Highway. Engin Geol, 53(3-4): 351-358.

Estabragh AR, Moghadas M, Javadi AA. 2013. Effect of different types of wetting fluids on the behaviour of expansive soil during wetting and drying. Soils Found, 53: 617-27.

Ferguson G. 1993. Use of self-cementing fly ashes as a soil stabilization agent, fly ash for soil improvement, Geotechnical Special Publication, 36, 1-15, Ed.: Sharp K.D., ASCE, New York.

Hasan H, Dang L, Khabbaz H, Fatahi B, Terzaghi S. 2016. Remediation of expansive soils using agricultural waste bagasse ash. Procedia Engin, 143: 1368-75.

Hausmann MR. 1990. Engineering principles of ground modification, McGraw-Hill, Singapore, 632.

Kolias S, Kasselouri-Rigopoulou V, Karahalios A. 2005. Stabilization of clayey soils with high calcium fly ash and cement, Cement Concrete Comp.

Prabakar J, Dendorkar N, Morchhale RK. 2004. Influence of fly ash on strength behavior of typical soils. Constr Build Material, 18(4): 263-267.

Puppala AJ. 2016. Advances in ground modification with chemical additives: From theory to practice. Transport Geotech, 9: 123-38.

Sabat AK, Muni PK. 2015. Effects of limestone dust on geotechnical properties of expansive soil. Int J Appl Eng Res, 10, 37724-37730.

Saeid A, Amin C, Hamid NA. 2012. Review on the lime and fly ash application in soil stabilization, IJBEES, 1, 3ISSN 2277 - 4394.

Sherwood P. 1993. Soil stabilization with cement and lime. State of the Art Review. London: Transport Research Laboratory, HMSO.

Thygaraj T, Sudhakar MR, Sai Suresh P, Salini U. 2012. Laboratory studies on stabilization of an expansive soil by lime precipitation technique. J Materials in Civil Engin, 24(8):1067-1075. 
Tosun H, Turköz M. 2000. Stabilisation of expansive clays with the hydrated Lime. Eighth National Congress of Soil Mechanics and Foundation Engineering, ITU, Istanbul.

Tumluer G. 2006. Shear strength of sand-mixed with cement. MSc Thesis, Çukurova University, Institute of Natural and Applied Sciences, Adana.

Ünver E. 2015. Stabilization of problematic clay soils with fly ash. MSc Thesis, Eskişehir Osmangazi University, Institute of
Natural and Applied Sciences, Eskișehir.

Wasemiller MA, Hoddinott KB. 1997. Testing soils mixed with waste or recycled materials. ASTM STP, 1275, Pennsylvania, 340.

Zhang T, Cai G, Liu S. 2017. Application of lignin-based byproduct stabilized silty soil in highway subgrade: A field investigation. J Cleaner Prod, 142:43-57. 